\title{
Salivary contribution to exhaled nitric oxide
}

\author{
W. Zetterquist*, C. Pedroletti ${ }^{+}$, J.O.N. Lundberg*, K. Alving*
}

\begin{abstract}
Salivary contribution to exhaled nitric oxide. W. Zetterquist, C. Pedroletti, J.O.N. Lundberg, K. Alving. C) ERS Journals Ltd 1999.

ABSTRACT: Dietary and metabolic nitrate is distributed from the blood to the saliva by active uptake in the salivary glands, and is reduced to nitrite in the oral cavity by the action of certain bacteria. Since it has been reported that nitric oxide may be formed nonenzymatically from nitrite this study aimed to determine whether salivary nitrite could influence measurements of exhaled NO.

Ten healthy subjects fasted overnight and ingested $400 \mathrm{mg}$ potassium nitrate, equivalent to $\sim 200 \mathrm{~g}$ spinach. Exhaled NO and nasal NO were regularly measured with a chemiluminescence technique up to $3 \mathrm{~h}$ after the ingestion. Measurements of exhaled NO were performed with a single-breath procedure, standardized to a 20-s exhalation, at a flow of $0.15 \mathrm{~L} \cdot \mathrm{s}^{-1}$, and oral pressure of 8-10 $\mathrm{cmH}_{2} \mathrm{O}$. Values of $\mathrm{NO}$ were registered as NO release rate $\left(\mathrm{pmol} \cdot \mathrm{s}^{-1}\right)$ during the plateau of exhalation.

Exhaled NO increased steadily over time after nitrate load and a maximum was seen at 120 min $\left(77.0 \pm 15.2\right.$ versus $\left.31.2 \pm 3.0 \mathrm{pmol} \cdot \mathrm{s}^{-1}, \mathrm{p}<0.01\right)$, whereas no increase was detected in nasal NO levels. Salivary nitrite concentrations increased in parallel; at $120 \mathrm{~min}$ there was a four-fold increase compared with baseline $(1.56 \pm 0.44$ versus $0.37 \pm 0.09 \mathrm{mM}, \mathrm{p}<0.05)$. The nitrite-reducing conditions in the oral cavity were also manipulated by the use of different mouthwash procedures. The antibacterial agent chlorhexidine acetate $(0.2 \%)$ decreased NO release by almost $50 \%(p<0.01) 90 \mathrm{~min}$ after nitrate loading and reduced the preload control levels by close to $30 \%(p<0.05)$. Sodium bicarbonate $(10 \%)$ also reduced exhaled NO levels, but to a somewhat lesser extent than chlorhexidine acetate.

In conclusion, salivary nitric oxide formation contributes to nitric oxide in exhaled air and a large intake of nitrate-rich foods before the investigation might be misinterpreted as an elevated inflammatory activity in the airways. This potential source of error and the means for avoiding it should be considered in the development of a future standardized method for measurements of exhaled nitric oxide.

Eur Respir J 1999; 13: 327-333.
\end{abstract}

*Division of Pharmacology, Dept of Physiology and Pharmacology, Karolinska Institute, Stockholm, Sweden. ${ }^{+}$Dept of Woman and Child Health, Karolinska Hospital, Stockholm, Sweden.

Correspondence: W. Zetterquist

Dept of Physiology and Pharmacology

Karolinska Institute

S-171 77 Stockholm

Sweden

Fax: 468332278

Keywords: Bacteria

exhaled air

nitric oxide

nitrite

nonenzymatic

saliva

Received: July 311998

Accepted after revision October 251998

Supported by the Swedish Medical Research Council (grant no. 10354), the Swedish Heart Lung Foundation and the Swedish Foundation for Health Care Science and Allergy Research.

In recent years there has been much interest in measurements of nitric oxide in exhaled air, since increased levels of NO were discovered in exhaled air of asthmatics [1] and enzymatically produced NO was suggested as a marker of inflammation in the respiratory tract $[2,3]$. However, several factors, such as mixing of NO originally produced in the paranasal sinuses, and variations in the degree of pressure and flow of the exhaled air, have been shown to influence and complicate the measurements [4]. These problems have created a need for a standardized method and a few articles have been published for methodological guidance $[3,5]$. Furthermore, a novel pathway of nonenzymatic NO production via chemical reduction of nitrite has recently been described $[6,7]$ and this might complicate the methodological approach even further.

A variable amount of nitrite, a potential substrate for NO formation, is found in the saliva as a product of nitrate reduction. The nitrate in the saliva comes from both metabolic and dietary sources, e.g. nitrate is found in large amounts in many green vegetables. After absorption in the gut, the nitrate is actively transported with the blood to the salivary glands and excreted with the saliva. Some of this nitrate is then reduced to nitrite by facultative anaerobic bacteria that colonize the oral cavity [8].

The aim of this study was to investigate whether nitrate ingestion could result in a significant NO formation from the saliva that would influence measurements of exhaled NO. Nasal NO levels were measured to determine whether a nitrate load could affect the NO formation in the nasal airways. Since the reduction of nitrite to NO is enhanced in an acidic environment [7], the $\mathrm{pH}$ in the oral cavity was altered by rinsing the mouth with different solutions. Ascorbic acid, which is a reductant on its own and an acid [9] was used to lower the $\mathrm{pH}$ and to demonstrate a rise in NO formation, and an alkaline solution, sodium bicarbonate, was used in an attempt to prevent the reduction of salivary nitrite to NO. A bacteriostatic composition, $0.2 \%$ chlorhexidine acetate, which would prevent the formation of nitrite from nitrate and thus give a diminished formation of NO, was also used. Chlorhexidine was chosen among other antibacterial agents since a previous study has reported that the reduction of nitrate is almost completely stopped after a single mouthwash with a $0.2 \%$ solution of the agent [10]. 


\section{Materials and methods}

All aspects of the study were approved by the local ethics committee.

\section{Measurements of nitric oxide in exhaled and nasal air}

Ten healthy, nonsmoking subjects (seven males), aged 23-43 yrs, were included in the study. The NO measurements were made using a chemiluminescense technique according to the recommendations recently described in a European Respiratory Society (ERS) Task Force Report [5] using a slow vital capacity exhalation manoeuvre (single-breath method).

The following describes briefly the single-breath method for exhaled air. NO-free air was continuously fed into a nondiffusing gas collection bag (Hans Rudolph, Kansas City, MO, USA) at a rate of $2-3 \mathrm{~L} \cdot \mathrm{min}^{-1}$. The bag was connected via a tube to a Y-piece with two one-way valves, which in turn was adapted to a mouthpiece. The subjects were asked to put their lips to the mouthpiece and inhale NO-free air from the gas collection bag. This was immediately followed by an exhalation with a flow rate of $0.15 \pm 0.02 \mathrm{~L} \cdot \mathrm{s}^{-1}$ against a resistance of $50 \mathrm{cmH}_{2} \mathrm{O} \cdot \mathrm{L}^{-1} \cdot \mathrm{s}$ (Hans Rudolph), giving rise to an oral pressure of 8-10 $\mathrm{cmH}_{2} \mathrm{O}$, for a period of $20 \mathrm{~s}$. The exhaled air exited through the other one-way valve in the Y-piece leading to a linear pneumotachymeter (Hans Rudolph), where flow and pressure were registered. A fraction of the exhaled air was sampled into the $\mathrm{NO}$ analyser (Eco Physics model CLD $700 \mathrm{AL}$ ) at a flow rate of $\sim 0.5 \mathrm{~L} \cdot \mathrm{min}^{-1}$, through a $110-\mathrm{cm}$ narrow-bore and Teflon-coated tube connected close to the mouthpiece. Signals from the pneumotachymeter and the NO analyser were sent to a computer for analysis by a specially designed software program (Exhaled Breath Analyser ${ }^{\mathrm{TM}}$, Aerocrine AB, Stockholm, Sweden). The recorded signals were visualized in real time on a computer screen, which enabled the subjects to maintain a certain flow (i.e. $0.15 \mathrm{~L} \cdot \mathrm{s}^{-1}$ ), adjusting the exhalation to a given flow range. The detected NO concentration was multiplied by the flow signal (Q) to give the NO release rate (pmol $\cdot \mathrm{s}^{-1}$ ), using the formula: $[\mathrm{NO}] \times \mathrm{Q}=\mathrm{pmol} \cdot \mathrm{L}^{-1} \times \mathrm{L} \cdot \mathrm{s}^{-1}$ $=\mathrm{pmol} \cdot \mathrm{s}^{-1}$. The conversion of $[\mathrm{NO}]$ from parts per billion (ppb) to $\mathrm{mol} \cdot \mathrm{L}^{-1}$ is derived from the fact that the volume of $1 \mathrm{~mol}$ of $\mathrm{NO}$ is $24.445 \mathrm{~L}$ at atmospheric pressure and room temperature $\left(25^{\circ} \mathrm{C}\right)$. Given this, $1 \mathrm{ppb}$ of $\mathrm{NO}$ equals $40.908 \mathrm{pmol} \cdot \mathrm{L}^{-1}$. The use of NO release, instead of NO concentration, has the advantage of taking the flow rate into account. However, if one were to convert it back to values of concentration, the NO release rate of $6.1 \mathrm{pmol} \cdot \mathrm{s}^{-1}$ equals $1 \mathrm{ppb}$ of $\mathrm{NO}$ using the flow rate of $0.15 \mathrm{~L} \cdot \mathrm{s}^{-1}$. Consequently, $61 \mathrm{pmol} \cdot \mathrm{s}^{-1}$ equals the concentration of $10 \mathrm{ppb}$ NO. In addition to the curves for flow and pressure, two curves for NO concentration and NO release were plotted on the screen and calculated mean values were presented for the last $40 \%$ of the breath, representing the plateau phase.

For nasal NO measurements, a nasal olive, tried out individually for a tight fit for each subject's nostrils, was attached to the Teflon-coated tube leading into the NO analyser. The olive was then placed in one of the nostrils, allowing the NO analyser to sample air from the nasal cavity with a flow rate of $0.5 \mathrm{~L} \cdot \mathrm{s}^{-1}$. In order to close the soft palate the subjects were asked to take a deep breath and exhale through the mouthpiece against the same resistance as above, while air was sampled from the nose. When this method was used, nasal NO values showed a stable plateau, visualized on the computer screen. The time for exhalation was set to $20 \mathrm{~s}$, which was quite sufficient to reach a plateau, and a mean value of the NO concentration during the last $40 \%$ of the exhalation was registered. Measurements were taken in both nostrils and the mean value was transformed into release rate by multiplying by the analyser sampling flow rate, in the same manner as above.

\section{Nitrate load}

The 10 subjects had fasted overnight and the experiments were performed in the morning. Baseline values of NO in exhaled air and from the nasal cavity were collected immediately before the ingestion of nitrate. Five single breaths were performed to obtain a mean value for the baseline. The measurements from the nasal cavity proved to be more reproducible; thus, one measurement from each nostril was considered adequate.

Potassium nitrate $(400 \mathrm{mg})$ was dissolved in a cup of distilled water $(150 \mathrm{~mL})$ and then ingested. This nitrate load is equivalent to, for example, $140 \mathrm{~g}$ lettuce or $200 \mathrm{~g}$ spinach. The subjects were asked to rinse their mouth with tap water after the ingestion. NO measurements in exhaled air (three exhalations) and from both nostrils were then taken at 5, 15, 30, 60, 90, 120, 150 and $180 \mathrm{~min}$.

A sample of saliva was taken immediately before and 60 and $120 \mathrm{~min}$ after the nitrate load for measurements of nitrate and nitrite concentration $(n=7)$. The subjects chewed on a small piece of Teflon plastic for $1 \mathrm{~min}$ and the saliva samples produced were stored at $-20^{\circ} \mathrm{C}$ for later analysis using a commercially available kit (Nitrate/Nitrite Assay kit, Cayman Chemical Company, Ann Arbor, MI, USA).

At $180 \mathrm{~min}$, measurements of exhaled NO were repeated immediately after mouthwash with sodium bicarbonate, to examine whether the possible reduction of $\mathrm{NO}$ formation by the mouthwash would be enhanced at a stage when one would expect high levels of nitrite. (For the mouthwash procedure see below.)

For the same reason a mouthwash experiment with chlorhexidine acetate $(0.2 \%)$ was conducted after nitrate loading. This was carried out on a separate day so as not to interfere with the original nitrate load. Exhaled NO (five exhalations) was measured $90 \mathrm{~min}$ after ingestion of potassium nitrate, as described above, whereafter mouthwash with chlorhexidine was performed (see below). Measurements of exhaled $\mathrm{NO}$ were repeated at $0,2,5,10,20$ and $30 \mathrm{~min}$ after the mouthwash.

\section{Nitric oxide formation from saliva in vitro}

On a separate occasion the subjects $(n=10)$ were asked to produce $10 \mathrm{~mL}$ saliva, without time restriction, by chewing on a piece of Teflon plastic. A 5-mL portion was placed in a $50 \mathrm{~mL}$ plastic syringe with an additional 0.5 $\mathrm{mL}$ of distilled water and the syringe was closed with a three-way stopcock after being filled up to $50 \mathrm{~mL}$ with 
NO-free air. The remaining $5-\mathrm{mL}$ portion of saliva was mixed with $0.5 \mathrm{~mL} 20 \mathrm{mM}$ nitrite solution (equivalent to $10 \mu \mathrm{mol}$ nitrite, resulting in a salivary nitrite concentration of $\sim 2 \mathrm{mM}$ ) and placed in another syringe filled up with NO-free air as above. The two syringes were incubated at $37^{\circ} \mathrm{C}$ for $15 \mathrm{~min}$. The air headspace was then collected and injected into the NO chemiluminescence analyser.

\section{Mouthwashes and nitric oxide in exhaled air}

In a series of experiments, the 10 subjects volunteered to have the NO in their exhaled air measured after rinsing their mouths with distilled water or solutions of sodium bicarbonate $(10 \%, \mathrm{pH} 7.85)$, ascorbic acid $(3 \%, \mathrm{pH} 2.5)$ and potassium nitrite $(1,10$ and $100 \mathrm{mM}$; $\mathrm{pH} 7.8-6.6)$ in a named order. Before the first mouthwash five baseline measurements of exhaled NO were taken to obtain a reference value. The liquid volume of all of the mouthwash solutions was set to $30 \mathrm{~mL}$, and the time for rinsing was set to $30 \mathrm{~s}$, whereupon the subjects spat out the solutions. Immediately after rinsing, the subjects put their lips to the mouthpiece and performed a single-breath manoeuvre, as described above. The single-breath measurement was then repeated after 1, 2 and $3 \mathrm{~min}$ for distilled water and sodium bicarbonate. For ascorbic acid and nitrite, exhaled NO was also measured after 4 and $5 \mathrm{~min}$. An interval of at least 10 min between the different mouthwash procedures was allowed to ensure that exhaled NO levels had returned to baseline.

Chlorhexidine acetate $0.2 \%(\mathrm{pH} 8.0)$ proved to have a long-lasting effect on the exhaled NO levels, so this mouthwash procedure was carried out on a separate day. Exhaled NO was measured immediately before (five exhalations) and $0,2,5,10,15$ and $20 \mathrm{~min}$ after rinsing with $25 \mathrm{~mL}$ of chlorhexidine for $30 \mathrm{~s}$.

\section{Analysis}

Baseline levels for each subject were calculated from the mean of five measurements of exhaled NO. At every time point after nitrate loading the mean values of three measurements was used for exhaled NO and the mean of the two values obtained from each nostril for nasal NO. After mouthwashes, only one measurement was taken at each time point. The changes in levels of NO were analysed using nonparametric analysis of variance (ANOVA) for repeated measures (Friedman) with subsequent Dunn's post-test. Nitrate and nitrite concentrations in the saliva were analysed by the nonparametric Wilcoxon signed rank test for paired measurements. The correlation between nitrite concentrations in saliva and exhaled NO levels was tested using the Spearman rank-order correlation coefficient. All statistical analyses were conducted using a statistical software package (InStat ${ }^{\mathrm{TM}}$; GraphPad Software, San Diego, CA, USA).

\section{Results}

\section{Nitrate load}

Exhaled levels of NO increased steadily after the nitrate ingestion, with a maximum at $120 \mathrm{~min}$. The NO release
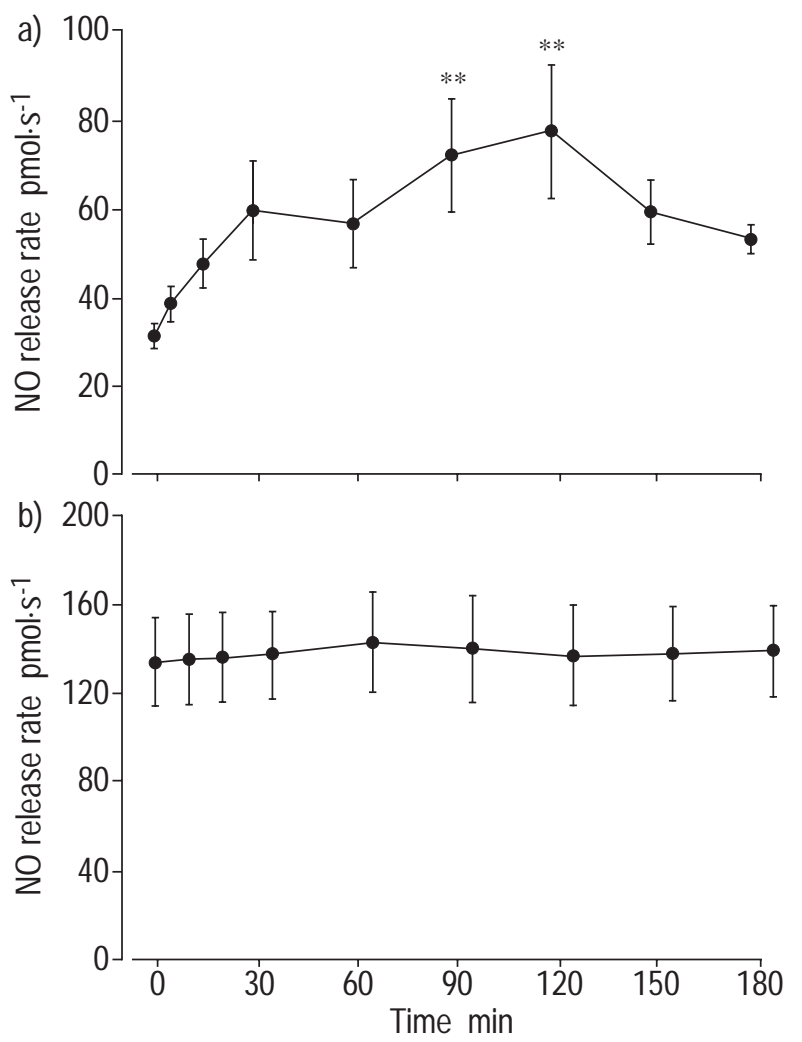

Fig. 1. - Nitric oxide measurements after nitrate intake. a) Increase of $\mathrm{NO}$ in exhaled air, registered as NO release rate $\left(\mathrm{pmol} \cdot \mathrm{s}^{-1}\right)$ during the plateau of a single-breath exhalation, after ingestion of $400 \mathrm{mg}$ potassium nitrate. b) Nasal NO release rate obtained by sampling air $(0.5$ $\mathrm{L} \cdot \mathrm{min}^{-1}$ ) from the nose in the same experiment. Values are expressed as mean $\pm \operatorname{SEM}(\mathrm{n}=10) . * *: \mathrm{p}<0.01$ compared with baseline.

rate had then increased by almost $150 \%$ (fig. 1a) compared with baseline.

The nitrate concentration in saliva showed a 10 -fold increase $60 \mathrm{~min}$ after the nitrate ingestion (fig. 2a). At 120 min the levels had again decreased. The nitrite concentration did not reach its peak until 120 min after the nitrate load (fig. 2b); thus, the time course parallelled the increase of NO in exhaled air. There was a trend towards a significant correlation between exhaled NO levels and salivary nitrite concentrations $(\mathrm{p}<0.10$, Spearman rankorder correlation coefficient).

No significant changes in NO production were found in the nose during the first $3 \mathrm{~h}$ following the nitrate loading (fig. 1b).

\section{Nitric oxide formation in saliva in vitro and in vivo}

The release of NO from incubated control saliva (nitrite concentration $<0.5 \mathrm{mM}$ ) resulted in a mean concentration of $\sim 60 \mathrm{ppb}$ in the air in the syringe. When nitrite was added to give a final concentration of $\sim 2 \mathrm{mM}$ the NO formation increased by $>500 \%(396.4 \pm 138.2$ versus $59.5 \pm 29.8$ ppb, p<0.01; fig. 3).

The addition of nitrite directly to the oral cavity also caused increased NO formation. Mouthwash with a $1 \mathrm{mM}$ potassium nitrite solution gave a small but nonsignificant increase in the plateau levels $\left(55.0 \pm 8.7 \mathrm{pmol} \cdot \mathrm{s}^{-1}\right)$, while the $100 \mathrm{mM}$ solution gave more than a 40 -fold increase compared with baseline $\left(1,791.8 \pm 404.8 \mathrm{pmol} \cdot \mathrm{s}^{-1}\right.$, fig. 4$)$. 

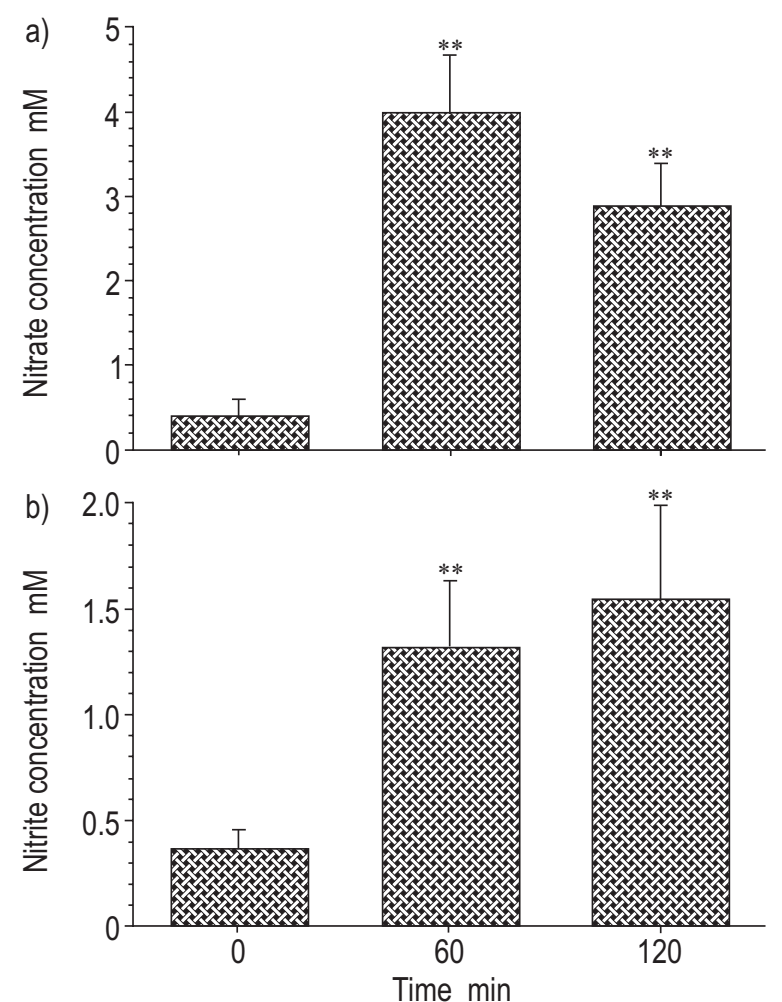

Fig. 2. - a) Nitrate and b) nitrite concentrations in saliva after nitrate intake. Samples were collected immediately before, and 60 and $120 \mathrm{~min}$ after ingestion of $400 \mathrm{mg}$ potassium nitrate. Values are expressed as mean \pm SEM $(n=7)$. **: $p<0.01$ compared with controls.

The kinetics of NO formation was studied after mouthwash with the $10 \mathrm{mM}$ nitrite solution. Plateau levels of exhaled NO showed a maximum at $60 \mathrm{~s}$ after the mouthwash and had returned to baseline at about 4 min (fig. $5 b$ ).

Increased levels of exhaled NO were also seen after rinsing with ascorbic acid. A marked but transient increase in the plateau values of NO was seen immediately after the mouthwash, with a relative increase of almost $300 \%$ compared with baseline (fig. 5a). The levels had returned to normal after $2 \mathrm{~min}$.

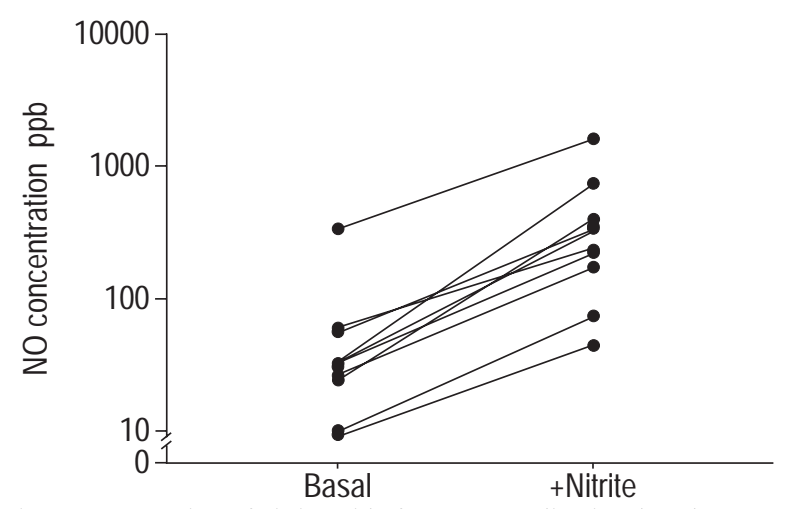

Fig. 3. - Formation of nitric oxide from $5 \mathrm{~mL}$ saliva incubated in vitro, with and without the addition of $0.5 \mathrm{~mL}$ of a $20 \mathrm{mM}$ nitrite solution (10 $\mu \mathrm{mol})$. Nitrite spiking resulted in a salivary nitrite concentration slightly $>2 \mathrm{mM}$, close to concentrations obtained after the ingestion of $400 \mathrm{mg}$ potassium nitrate. $\mathrm{NO}$ concentration was measured in $50 \mathrm{~mL}$ of headspace air that had been incubated with the saliva at $37^{\circ} \mathrm{C}$ for $15 \mathrm{~min}$. The average increase exceeded $500 \%$ (396.4 \pm 138.2 versus $59.5 \pm 29.8$ parts per billion (ppb), $\mathrm{p}<0.01, \mathrm{n}=10)$.

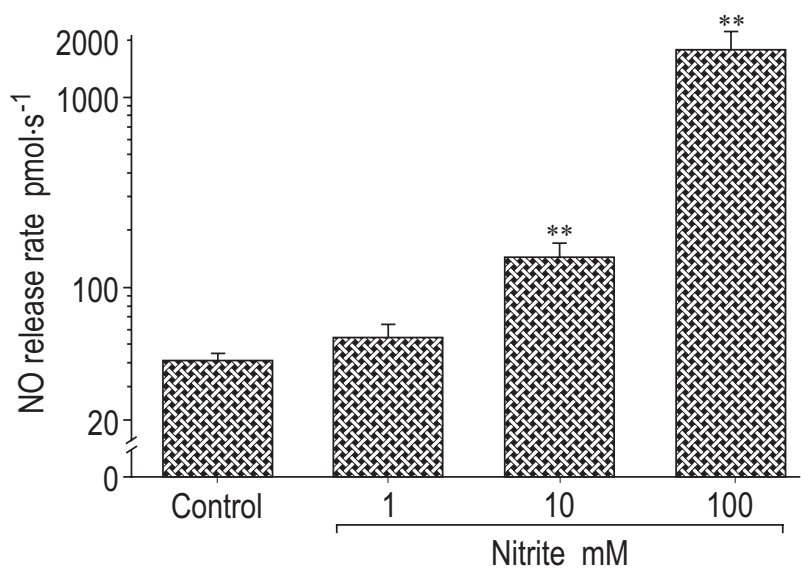

Fig. 4. - Dose-response pattern of nitric oxide release rate in exhaled air after mouthwash with nitrite solutions of increasing concentrations. Values are expressed as mean \pm SEM $(\mathrm{n}=10)$. $* *: \mathrm{p}<0.01$ compared with controls.

\section{Mouthwash and reduction of nitric oxide in exhaled air}

Mouthwash with distilled water gave a small decrease in exhaled plateau levels of NO but the change did not reach statistical significance, mainly owing to a large interindividual variation. However, there was no effect on the NO levels immediately after the mouthwash; rather, the slight reduction was seen after 1-2 min (fig. 6a).

Mouthwash with sodium bicarbonate $(10 \%)$ was more efficient and consistent in reducing the plateau levels. Exhaled NO was significantly reduced immediately after the mouthwash, by about $25 \%$ (fig. 6b). At $60 \mathrm{~s}$, but not at $120 \mathrm{~s}$, the release rate of NO was still significantly lower than baseline.

The mouthwash performed with sodium bicarbonate 180 min after nitrate load gave an even larger relative decrease; the plateau was reduced by $>30 \%(36.2 \pm 4.2$ versus $\left.52.7 \pm 4.8 \mathrm{pmol} \cdot \mathrm{s}^{-1}, \mathrm{p}<0.01\right)$.

The antibacterial agent chlorhexidine acetate $(0.2 \%)$ was more efficient than sodium bicarbonate in decreasing the NO levels and the effect of one mouthwash was also longer lasting. The immediate decrease was almost 30\% compared to baseline levels (fig. 7a). The mean values for NO release were slightly lower than the baseline levels throughout the measurement period $(20 \mathrm{~min})$, but some interindividual variation was noted.

In the experiment with chlorhexidine mouthwash after nitrate loading the mean values for NO release $90 \mathrm{~min}$ after the load showed an almost two-fold increase compared with control levels $\left(60.8 \pm 6.4\right.$ versus $34.8 \pm 4.2 \mathrm{pmol} \cdot \mathrm{s}^{-1}$, $\mathrm{p}<0.01)$. Mouthwash with chlorhexidine acetate led to an immediate reduction in the NO levels, close to $50 \%$ (fig. $7 b)$. The NO release also remained significantly reduced up to $30 \mathrm{~min}$ after the mouthwash.

\section{Discussion}

Many recent studies have shown that the levels of exhaled NO are increased in airway inflammation. It has, therefore, been suggested that measurement of $\mathrm{NO}$ in exhaled air, as a rapid and noninvasive test, may be useful 

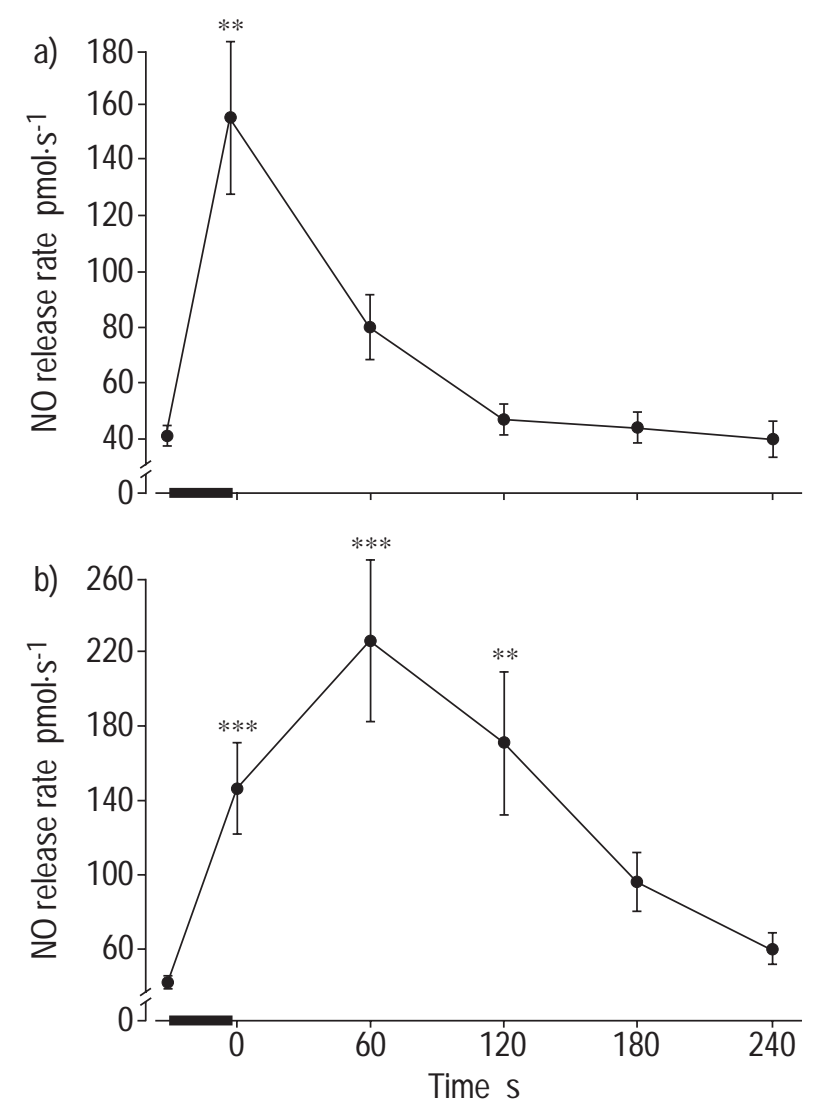

Fig. 5. - Increased nitric oxide release into exhaled air after mouthwash with a) ascorbic acid (3\%) and b) $10 \mathrm{mM}$ potassium nitrite. The bar on the time scale represents the 30 -s mouthwash period. Values are expressed as mean $\pm \operatorname{SEM}(\mathrm{n}=10) . * *: \mathrm{p}<0.01 ; * * *: \mathrm{p}<0.001$, compared with baseline.

in the diagnosis and therapy monitoring of asthma. The factors influencing exhaled NO in normal subjects are, however, not fully understood. This study has shown that exhaled NO levels are greatly increased by ingestion of nitrate, which is a normal constituent in the daily diet. Using the present method, NO release values above 60 $\mathrm{pmol} \cdot \mathrm{s}^{-1}$ were interpreted as an elevated inflammatory activity in the airways (unpublished data) and mean levels were obtained that were well above that after nitrate ingestion. These observations indicate that this increase is probably due to NO release from the saliva. This is supported by the fact that the NO level in exhaled air is elevated in a parallel pattern to the nitrite concentration in saliva. Moreover, formation of NO could be detected in saliva in vitro and this was greatly enhanced when nitrite was added to the saliva in an amount calculated to correspond to the concentrations obtained after ingestion of $\sim 200 \mathrm{~g}$ spinach. Furthermore, a reduction in exhaled NO was seen with an antibacterial and an alkaline mouthwash, both of which were used to prevent the potential nonenzymatic pathway of NO production in the oral cavity. The relative reduction was also increased when the subjects had high concentrations of nitrite in the saliva, i.e. after nitrate loading. Finally, a nonenzymatic NO formation in the oral cavity has already been described by DunCAN et al. [11] in a recent study. However, in that study no attempts were made to connect this to measurements of NO in exhaled air. Thus, it has not previously been described
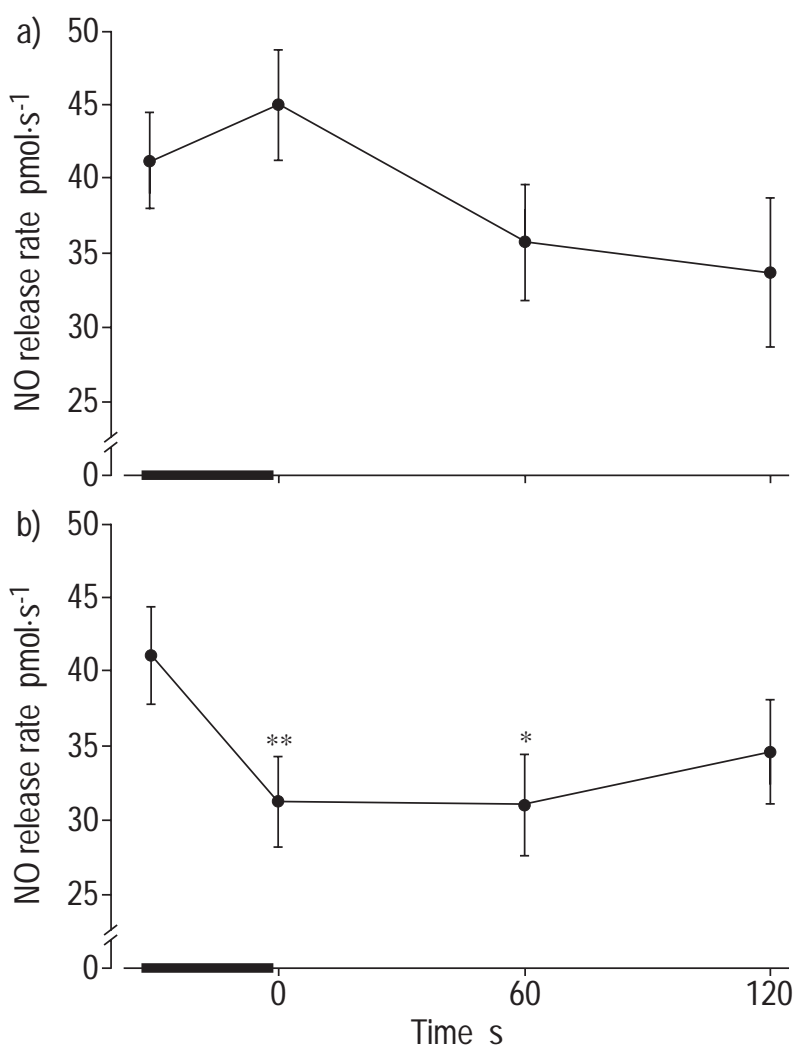

Fig. 6. - Effects of mouthwash with a) distilled water and b) sodium bicarbonate $(10 \%)$ on the nitric oxide release rate. The bar on the time scale represents the 30 -s mouthwash period. Values are expressed as mean $\pm \operatorname{SEM}(\mathrm{n}=10) . *: \mathrm{p}<0.05 ; * *: \mathrm{p}<0.01$, compared with baseline.

whether NO from the saliva can actually contribute to exhaled NO and whether this can interfere with the standard measuring procedure.

The present results, from the manipulation of the nitrite content in saliva and by using different mouthwashes, pose an interesting question about the origin of the NO normally seen during the plateau of an oral single-breath exhalation. It is generally considered that the plateau represents NO derived primarily from the lower respiratory tract [5]. The present findings, however, raise some doubts about that notion, since the increase of NO in question came from the saliva and yet there was a marked influence on the plateau levels. Accordingly, it seems as if not only the first part of the exhaled air, i.e. air derived from the dead-space area, but also the plateau may consist of NO from the upper respiratory tract. Thus, there is a continuous release of NO from the saliva and the tissues in the upper airways that mixes with the whole exhaled volume.

The influence of dietary nitrates on exhaled NO levels could, furthermore, explain the intra- and interindividual differences seen in normal subjects. Additionally, it could be responsible for the varying reference values reported for exhaled NO in healthy controls, even though other confounding factors, such as unforeseen atopy or different measuring procedures, could also account for this. The influence of dietary nitrates does, however, not diminish the value of exhaled NO as a marker of allergic airway inflammation since a number of previous studies, where this confounding factor was not considered, have shown significantly higher levels of exhaled NO in asthmatic 

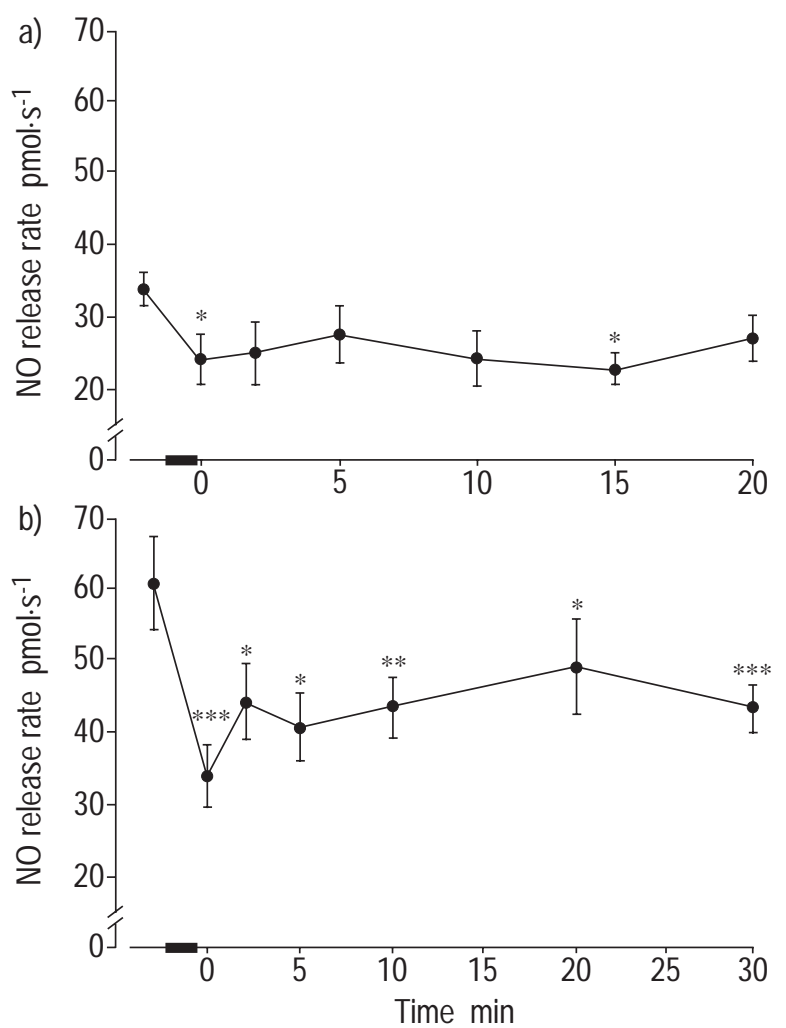

Fig. 7. - Effects on exhaled nitric oxide by mouthwash with chlorhexidine acetate $(0.2 \%)$. a) Decrease in nitric oxide levels after chlorhexidine rinsing in control (fasting) situation. b) Subjects pretreated with $400 \mathrm{mg}$ potassium nitrate $90 \mathrm{~min}$ before baseline measurement and the subsequent mouthwash. The bar on the time scale represents the 30-s mouthwash period. Values are expressed as mean \pm SEM $(n=10)$. $*$ : $\mathrm{p}<$ $0.05 ; * *: \mathrm{p}<0.01 ; * * *: \mathrm{p}<0.001$, compared with controls.

subjects. Furthermore, in pilot studies performed on a few asthmatics only a slight decrease in exhaled NO levels was seen after mouthwash with sodium bicarbonate; in absolute numbers about the same decrease as seen in the healthy subjects in the present study (unpublished data). It is, rather, a question of different sources for NO production: if one is aware of the salivary formation, and by different means tries to exclude this component, the accuracy of the test would be increased further.

A clear increase in the mean nitrite concentration in saliva parallel to the increase of the mean NO level in exhaled air was seen, but the correlation did not turn out to be significant. There could be several explanations for this. One is probably the individual differences in salivary $\mathrm{pH}$ and hence a variable ability of the saliva to reduce nitrite to NO. A difference in the amount of saliva in the oral cavity during the single-breath measurements is another probable reason not to expect an entirely linear correlation between salivary nitrite concentrations and exhaled NO levels. Ascorbic acid is present to a varying degree in the saliva [12] and this could be yet another factor influencing the correlation, since ascorbic acid enhances the reduction of nitrite to $\mathrm{NO}$ regardless of $\mathrm{pH}$ [9]. A future study design that accounts for these varying factors would probably give a stronger correlation between nitrite concentrations and exhaled NO.

It was less surprising that the nitrate ingestion did not alter nasal NO levels, since no secretion of nitrate to the respiratory epithelium of the paranasal sinuses has been described. Thus, the NO derived from the nose seems to be synthesized enzymatically, from L-arginine by nitric oxide synthase, without any contribution from nonenzymatic NO. The enzymatic NO production in the nasal airways has been described in detail previously $[13,14]$.

Nitrite rinsing was included in the study to provide further evidence for the possibility of $\mathrm{NO}$ formation from nitrite in the oral cavity. The great increase in exhaled NO obtained after mouthwash with high concentrations of nitrite indicated that the nitrite reducing potential in the oral cavity is not limited, whereas the nitrite concentration may be the rate-limiting factor.

The large but transient increase in NO formation seen after mouthwash with ascorbic acid is due to an enhanced reduction because of the lowered $\mathrm{pH}[6,7]$ and to the reducing ability of ascorbic acid itself [9]. One could speculate that elevated levels of ascorbic acid in the saliva, due to an excessive intake, would give rise to a significant increase of NO in exhaled air. However, previous reports have shown that salivary ascorbate levels remain unchanged in spite of an enhanced intake and that there is no relation between salivary and plasma ascorbate concentrations, even though individual differences in salivary levels can be seen [12].

Mouthwash with distilled water had no immediate effect on exhaled NO levels, which indicates that rinsing the oral cavity per se is not adequate to affect oral NO formation to any great extent. However, a slight decrease in NO levels was observed after a couple of repeated measurements. This could be due to an increased dryness in the oral cavity and the upper airways, since the NO-free air inhaled from the Hans Rudolph bag was considered by the subjects to be quite dry; several subjects complained about an intensified dryness of the mouth and even a slight irritation in the bronchi after a few measurements repeated with only a short interval.

The mouthwash with sodium bicarbonate did, however, result in an immediate decrease in the plateau levels of exhaled NO. This decrease from normal levels indicates that there is a slight contribution of salivary NO under ordinary conditions, i.e. not only after the intake of large amounts of nitrate. This contribution may be minor under normal circumstances, but the notion of a small but continuous contribution of NO from the saliva is, nevertheless, of much interest as it sheds some light on the origin of the NO found in exhaled air in normal subjects. For example, it indicates that the low levels of NO seen in normal subjects are not a product of inflammatory activity, but may merely reflect a possible system for primary host defence $[7,11]$. The effects of sodium bicarbonate rinsing were, as expected, even more powerful after nitrate ingestion. However, rinsing did not return the NO levels all the way to the baseline values. One factor that might prevent this procedure from being fully efficient is that the $\mathrm{pH}$ of the sodium bicarbonate solution was close to the $\mathrm{pH}$ optimum of nitrate reductase [10], which could cause the formation of larger amounts of nitrite. Another problem that may limit the use of sodium bicarbonate solution as a standard mouthwash procedure is its disagreeable taste. Sodium bicarbonate seems, however, to be able to diminish NO formation in the oral cavity and could be a prototype for the development of a future mouthwash solution. 
The chlorhexidine acetate solution seemed to be the most efficient mouthwash to prevent the formation of $\mathrm{NO}$ in the oral cavity. As with sodium bicarbonate the effect was more marked after nitrate loading. One explanation for the efficacy of this procedure may be the antiseptic action of chlorhexidine acetate that would prevent the facultative anaerobic bacteria from converting nitrate to nitrite. This effect should, theoretically, give a more prolonged decline of nitrite and NO formation after a single mouthwash. Indeed, a more sustained decrease of exhaled NO levels was seen after chlorhexidine treatment. However, the most prominent reduction was obtained immediately after the mouthwash, whereupon the NO release gradually picked up. Since it is unlikely that the bacteria would regain metabolic activity so quickly, it is unlikely that the immediate effect of the chlorhexidine is entirely due to its antiseptic properties. The immediate fall in exhaled NO levels might, instead, be explained by an additive but short-lived effect of the alkaline $\mathrm{pH}$ of the solution (8.0). Even though the results from rinsing with chlorhexidine acetate were promising it is not an optimal solution, mainly because of its very disagreeable taste, as in the case of sodium bicarbonate. Thus, a solution that could be used as a standardized mouth-rinsing method in the clinic remains to be developed.

In summary, this study has shown that there is a considerable contribution to exhaled nitric oxide from nonenzymatically formed nitric oxide derived from nitrite in the saliva. There is probably a minor addition of salivary nitric oxide to the exhaled air under normal conditions, but the intake of no more than $200 \mathrm{~g}$ of spinach or half that amount of lettuce, a few hours before a measurement of exhaled nitric oxide, might result in levels that could be misinterpreted as an elevated inflammatory activity in the airways. This potential source of error should be taken into consideration before measurements of exhaled nitric oxide are made, which will create a need for a standardized method to reduce this nitric oxide source. The simplest way would probably be to create a standard of food restriction, where the patients are asked to avoid the intake of certain vegetables for a few hours before the medical examination. However, to have more control, the addition of a mouthwash procedure immediately before the nitric oxide measurement may be preferable.

\section{References}

1. Alving K, Weitzberg E, Lundberg JM. Increased amounts of nitric oxide in exhaled air of asthmatics. Eur Respir $J$ 1993; 6: 1368-1370.

2. Barnes P, Kharitonov S. Exhaled nitric oxide: a new lung functional test. Thorax 1996; 51: 233-237.

3. Lundberg JON, Weitzberg E, Lundberg JM, Alving K. Nitric oxide in exhaled air. Eur Respir J 1996; 9: 26712680.

4. Silkoff PE, McClean PA, Slutsky AS, et al. Marked flowdependence of exhaled nitric oxide using a new technique to exclude nasal nitric oxide. Am J Respir Crit Care Med 1997; 155: 260-267.

5. Kharitonov S, Alving K, Barnes P. Exhaled and nasal nitric oxide measurements: recommendations. Eur Respir $J$ 1997; 10: 1683-1693.

6. Benjamin N, O'Driscoll F, Dougall H, Duncan C, Smith L, Golden M. Stomach NO synthasis. Nature 1994; 368: 502.

7. Lundberg JON, Weitzberg E, Lundberg JM, Alving K. Intragastric nitric oxide production in humans: measurements in expelled air. Gut 1994; 35: 1543-1546.

8. Tannenbaum SR, Weissman M, Fett D. The effect of dietary nitrate intake on nitrate formation in human saliva. Food Cosmetics Toxical 1976; 14: 549-552.

9. Lundberg JON, Carlsson S, Engstrand L, Morcos E, Wiklund NP, Weitzberg E. Urinary nitrite: more than a marker of infection. Urology 1997; 50: 189-191.

10. van Maanen JM, van Geel AA, Kleinjans JC. Modulation of nitrate-nitrite conversion in the oral cavity. Cancer Detect and Preven 1996; 20: 590-596.

11. Duncan C, Douglas H, Johnston P, et al. Chemical generation of nitric oxide in the mouth from the enterosalivary circulation of dietary nitrate. Nature Med 1995; 1: 546551.

12. Leggott P, Robertson P, Rothman D, Murray P, Jacob R. Response of lingual ascorbic acid test and salivary ascorbate levels to changes in ascorbic acid intake. J Dent Res 1986; 65: 131-134.

13. Lundberg JON, Farkas-Szallasi T, Weitzberg E, et al. High nitric oxide production in human paranasal sinuses. Nature Med 1995; 1: 370-373.

14. Lundberg JON, Weitzberg E, Rinder J, et al. Calciumindependent and steroid-resistant nitric oxide synthase activity in human paranasal sinus mucosa. Eur Respir $J$ 1996; 9: 1344-1347. 